\title{
AVALIAÇÃO DA ILUMINÂNCIA NA IMPLANTAÇÃO E MANUTENÇÃO FLORESTAL NAS MICRORREGIÕES CAPARAÓ E CENTRO SUL DO ESPÍRITO SANTO
}

\author{
Filipe de Moraes ${ }^{1}$ \\ Rômulo Maziero² \\ Nilton Cesar Fiedler ${ }^{3}$ \\ Flávio Cipriano de Assis do Carmo ${ }^{4}$ \\ Elizabeth Neire da Silva Oliveira de Paula ${ }^{5}$
}

Resumo: Como importante segmento, o setor florestal depende diretamente de mão de obra para execução das atividades, sendo que, esse fator necessita de atenção no âmbito de melhores condições de trabalho. Este estudo teve o objetivo de avaliar a iluminância durante a execução de atividades florestais realizadas nas microrregiões Caparaó e centro sul do estado do Espírito Santo. A pesquisa foi realizada em áreas florestais de produção de eucalipto, nos municípios de Alegre, Jerônimo Monteiro e Guaçuí, no período de outubro de 2012 a maio de 2013. Inicialmente foram levantadas as atividades do ciclo de trabalho e determinou-se o número mínimo de amostras necessárias em cada fase da pesquisa. Foram avaliadas as atividades de adubação, capina química, coroamento, coveamento, desrama manual, desrama semimecanizada e roçada semi-mecanizada, e os resultados a legislação. Observou-se que em todas as atividades os níveis de iluminância foram aceitáveis, sendo superior ao mínimo de acordo com a NBR 5413 (1992). Mas há necessidade de proteção especial para a visão, principalmente nos horários de maior irradiação solar.

Palavras-chave: Ambiente de trabalho; Condições ambientais; Trabalhadores florestais.

\footnotetext{
1 Universidade Federal do Espírito Santo, Brasil. E-mail: filipe_ilhag@hotmail.com.

2 Universidade Federal do Espírito Santo, Brasil. E-mail: maziero.ufes@gmail.com.

3 Universidade Federal do Espírito Santo, Brasil. E-mail: niltoncesarfiedler@yahoo.com.br.

${ }^{4}$ Universidade Federal do Espírito Santo, Brasil. E-mail: flaviocipriano@yahoo.com.br.

${ }^{5}$ Universidade Federal do Espírito Santo, Brasil. E-mail: e_neire@yahoo.com.br.
} 